\title{
Psychic suffering and depression in black children and adolescents: systematic review and meta- analysis
}

\author{
J.M.M. Landim ${ }^{1 \oplus 凶}$, M.L. Rolim Neto ${ }^{2 \oplus}$, and D.M. Christofolini ${ }^{1 \oplus}$ \\ ${ }^{1}$ Centro Universitário FMABC, Santo André, SP, Brasil \\ ${ }^{2}$ Universidade Federal do Cariri, Juazeiro do Norte, CE, Brasil
}

\begin{abstract}
Depression is a common disorder in the population, but some people are more vulnerable to this condition. Groups at higher risk of developing psychic suffering include black children and adolescents living in vulnerable socioeconomic conditions. This study aimed to analyze race and life conditions as determinants of depression in children and adolescents. This was a systematic review with meta-analysis. The study sources were MEDLINE Ovid, Web of Science, Latin American and Caribbean Health Science Information database, Science Citation Index-Expanded, PubMed, EMBASE, and Scopus. The following keywords were used: Child, Adolescent, Stress, Psychological, Depression, and African Continental Ancestry Group, using the logical operators AND and OR. The general criteria were observational studies published in the last 20 years. Language was not restricted to avoid possible bias in the selection of articles. Studies with a high risk of bias were excluded. General analysis was conducted with RStudio 3.0 software using odds ratio analysis with a 95\% confidence interval and 0.05 significance level. We firstly found 654 studies, of which 18 met the criteria and were included in this review. Race and life conditions were determinants of depression in children and adolescents, with a negative impact for the black population.
\end{abstract}

Key words: Depression; Children; Adolescents; Black person

\section{Introduction}

Depression is a psychological condition affecting around $6 \%$ of the world's population. Factors like socioeconomic variables, health, and race may contribute to a higher level of predisposition to the disease (1). In children and adolescents, these predictors may be even stronger and have significant impact on mental health, especially in black individuals (2).

Low educational and income levels and use of drugs are some of the points that should be considered. When these factors are associated with race-based prejudice, the association with mental dysfunctions, including depression, is stronger (3). These variables must be analyzed so that intervention strategies can be determined.

Factors that have longitudinal prejudice have interpersonal and transactional sides. Therefore, not only personal but also external factors may influence the process of mood disorders (4). The presence of other related diseases, such as infections, has a cause-effect relationship with psychic suffering (5).
Based on these effects, we need to take into consideration several conditions and narratives associated with children, adolescents, and their families that, in general, have a higher risk of developing mental diseases like depression. Thus, analysis of these factors is fundamental to determine strategies to be adopted in this group.

Hence, are race and socioeconomic conditions significant determinants of depression in children and adolescents?

The relationship between race and depression is wellknown, but a meta-analysis of published results is lacking. In addition, the inclusion of possible associated factors in the analysis allowed us to verify whether there is a significant impact for children and adolescents that could generate life-long changes. Thus, this global analysis, involving samples from different groups, has a gap that needs to be filled.

This study aimed to analyze whether race and life conditions are determinants of depression in children and adolescents. 


\section{Material and Methods}

A systematic review with meta-analysis was carried out according to the recommendations of the PRISMA protocol (identification number 259534) (6).

Qualitative and quantitative epidemiological studies were included to allow the calculation of the effects of each analyzed variable/group. The general inclusion criteria were observational studies published in the last 20 years. Language of publication was not restricted to avoid possible bias in the selection of studies. Studies with a high risk of bias were excluded.

We included studies with black children and adolescents from Portuguese-speaking countries for an analysis of the potential risk factors and determinants of depression. We assessed variables that could be considered sources of influence according to the PVO acronym (Population, Variables, and Outcomes), as follows: P: Portuguesespeaking black children and adolescents; V: socioeconomic and skin color vulnerability; O: depression.

We removed studies that discussed these aspects in a sporadic way so that they did not influence the results. For effect determination, the primary outcomes were depression and general psychic suffering and the secondary outcome was other mental disorders. The search was performed in MEDLINE Ovid, Web of Science, Latin American and Caribbean Health Science Information, Science Citation Index-Expanded PubMed, EMBASE, and Scopus electronic databases.

The search strategy used in all databases was based on previous searches and included the words: (Child OR Adolescent) AND (Stress, Psychological OR Depression) AND ("African Continental Ancestry Group").

Two reviewers and authors worked independently to extract predetermined information. In the event of a discrepancy, a third reviewer was consulted for data determination and inclusion or removal of the article. The search was conducted in the first semester of 2020 (March 25 to June 26). Restricted articles were obtained through contact with the researcher, and other studies were used to complement the discussion and general idea of the systematic review. A final search in related sources, such as preprints or partial data, was carried out to determine the final sample of studies.

The information collected from each study was: year of publication, country of origin, authors, method, number of subjects, inclusion and exclusion criteria, screening forms, and baseline characteristics of subjects.

For the analysis of outcomes, we collected the number of subjects and mean and standard deviation of descriptive variables. Two authors worked independently in the process of searching and selecting studies using the Rayyan software (https://www.rayyan.ai/). In case of disagreement between the researchers, a third reviewer was consulted to determine whether or not to include the study.
Analysis of the effects was done according to dichotomous or continuous data, based on the characteristics of the selected studies and using a 95\% confidence interval $(\mathrm{Cl})$. Whenever possible, we searched for absent data and the multiple imputation method was used for missing cases.

Heterogeneity refers to the extent to which studies in a review differ from each other. We chose the most homogeneous studies for a better determination of effects. Studies with $1^{2}$ above $50 \%$ were considered heterogeneous. The analysis was done with RStudio 3.0 software (https://cran.r-project.org/bin/windows/base/) using the meta package and odds ratio analysis with a $95 \% \mathrm{Cl}$ and 0.05 significance level. Summary estimates were calculated for each study such as sample percentages, means, standard deviations, and measures of association when available.

\section{Results}

We firstly found 654 studies, of which 18 met the criteria and were included in the review. The flowchart in Figure 1 summarizes the study selection. With the use of the Rayyan tool, 132 studies were excluded, as they were not within the scope of our study.

Table 1 shows the main characteristics of the studies, including authors, objective, method, and main outcomes. Most of the selected studies were observational and the

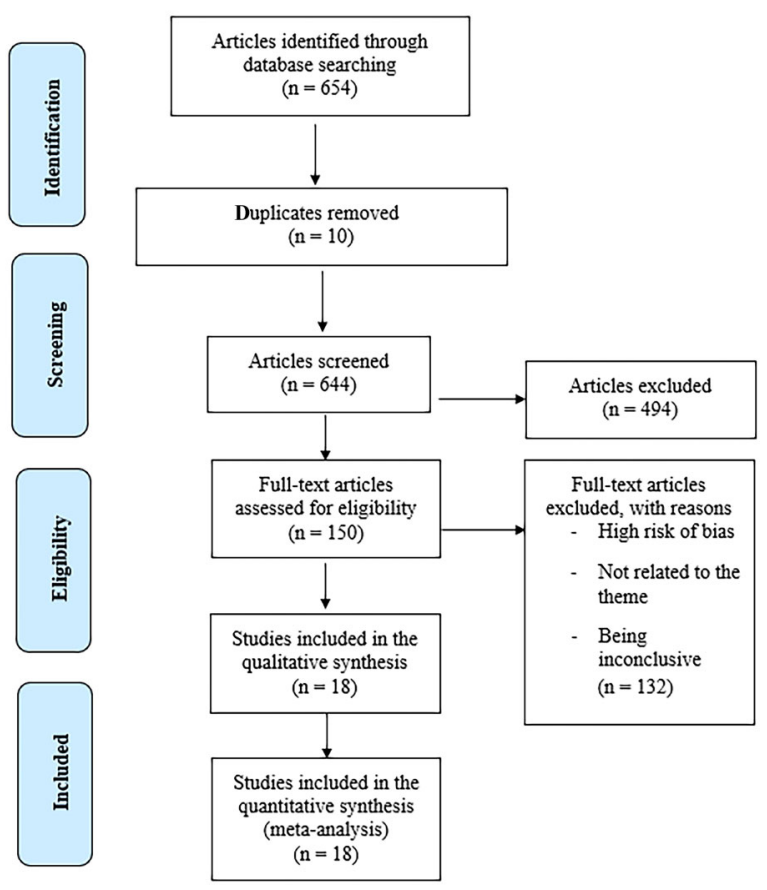

Figure 1. PRISMA flow diagram of study selection. 
Table 1. Synthesis of the selected studies.

\begin{tabular}{|c|c|c|c|}
\hline Author (reference) & Objective & Method & Main outcomes \\
\hline Rotheram-Borus et al. (1) & $\begin{array}{l}\text { To analyze depression through the presence of } \\
\text { comorbidities }\end{array}$ & Cohort & $\begin{array}{l}\text { Alcohol abuse, income, and diseases like } \\
\text { HIV influence depression development }\end{array}$ \\
\hline Mellick et al. (2) & $\begin{array}{l}\text { To analyze the invariance of classifications of } \\
\text { depression symptoms in African American, } \\
\text { Hispanic/Latin, and Caucasian adolescents } \\
\text { that are psychiatric patients }\end{array}$ & Cross-sectional & Ethnicity is a risk factor for mental diseases \\
\hline Hazzard et al. (3) & $\begin{array}{l}\text { To examine the association of mental disorders } \\
\text { in adolescents with differences of skin color/ } \\
\text { race }\end{array}$ & Longitudinal & $\begin{array}{l}\text { The early identification of these cognitions } \\
\text { and early intervention may help reduce the } \\
\text { risk of depression in the young adult age. }\end{array}$ \\
\hline Davis et al. (4) & $\begin{array}{l}\text { To examine the paths between victimization, } \\
\text { depression, academic performance, and } \\
\text { problematic consumption in adolescents }\end{array}$ & Cross-sectional & $\begin{array}{l}\text { Results are discussed regarding the } \\
\text { prevention interventions for problematic } \\
\text { consumption, as well as screening for } \\
\text { adolescent depression }\end{array}$ \\
\hline Earnshaw et al. (5) & $\begin{array}{c}\text { To analyze the problems related to stigma, } \\
\text { depression, and use of substances among } \\
\text { young people }\end{array}$ & Cross-sectional & $\begin{array}{l}\text { The internalized stigma is associated with a } \\
\text { higher risk of depression, and the associative } \\
\text { stigma is associated with a higher risk of } \\
\text { depression and problems related to } \\
\text { substance use }\end{array}$ \\
\hline Weller et al. (7) & $\begin{array}{c}\text { To estimate the national prevalence of } \\
\text { comorbidities for black, Hispanic, and white } \\
\text { adolescents separately and compare the } \\
\text { prevalence of comorbidities among } \\
\text { adolescents with and without depression }\end{array}$ & Cross-sectional & $\begin{array}{l}\text { This study found important differences in the } \\
\text { prevalence of comorbid psychiatric conditions } \\
\text { by race/ethnicity. Results highlight the need of } \\
\text { interventions directed to black and Hispanic } \\
\text { adolescents with depression that are } \\
\text { simultaneously treating anxiety and } \\
\text { behavioral problems. }\end{array}$ \\
\hline Hussen et al. (8) & $\begin{array}{c}\text { To analyze social capital, depressive } \\
\text { symptoms, and viral suppression of HIV among } \\
\text { black, gay, bisexual, and other kinds of } \\
\text { adolescents that have sexual intercourse with } \\
\text { men living with HIV }\end{array}$ & Cross-sectional & $\begin{array}{l}\text { Socioeconomic factors are a risk for the } \\
\text { development of mental comorbidities }\end{array}$ \\
\hline Kilpatrick and Taylor (9) & $\begin{array}{l}\text { To assess the importance of perceived } \\
\text { prejudice in a multiethnic sample of study } \\
\text { participants with and without physical disability }\end{array}$ & Cross-sectional & $\begin{array}{l}\text { Results show race as a source of prejudice } \\
\text { and health risk }\end{array}$ \\
\hline Mowbray et al. (10) & To analyze race as a depression determinant & Cross-sectional & Race is a risk factor for depression \\
\hline Assari et al. (11) & $\begin{array}{l}\text { To investigate the association between family } \\
\text { income and risk of major depressive disorder } \\
\text { (MDD) in black young individuals, based on }\end{array}$ & Cross-sectional & $\begin{array}{l}\text { Results suggest that ethnicity and gender } \\
\text { influence how socioeconomic resources, like } \\
\text { income, are associated with risk of MDD }\end{array}$ \\
\hline
\end{tabular}

\begin{tabular}{|c|c|c|c|}
\hline Bromberger et al. (12) & $\begin{array}{c}\text { To analyze childhood socioeconomic } \\
\text { circumstances and depressive load of } \\
\text { symptoms throughout } 15 \text { years of follow-up in } \\
\text { midlife }\end{array}$ & Cohort & $\begin{array}{l}\text { Socioeconomic factors can be mental health } \\
\text { determiners }\end{array}$ \\
\hline Youssef et al. (13) & $\begin{array}{l}\text { To examine: } 1 \text { ) if there is a dose-response } \\
\text { relation between trauma and depressive } \\
\text { symptoms; } 2 \text { ) if the initial trauma affected } \\
\text { European Americans (AE) and African } \\
\text { Americans }(\mathrm{AA}) \text { in a similar way; and } 3 \text { ) if } \\
\text { resilience reduces the trauma effect }\end{array}$ & Cross-sectional & $\begin{array}{l}\text { Even though the adverse experiences have } \\
\text { been significantly associated with the } \\
\text { depression severity of the dose-response } \\
\text { form, a higher resilience mitigated the impact } \\
\text { of childhood adversities in depressive } \\
\text { symptoms in young adults }\end{array}$ \\
\hline Jesse et al. (14) & $\begin{array}{l}\text { To analyze the role of routine events in } \\
\text { depression }\end{array}$ & Cross-sectional & $\begin{array}{c}\text { Impact on mental health of being young and } \\
\text { black is significant }\end{array}$ \\
\hline Montalvo-Liendo et al. (15) & $\begin{array}{c}\text { To analyze the ethnical-race variation for } \\
\text { depression }\end{array}$ & Cross-sectional & $\begin{array}{l}\text { Even though it is important to assess the } \\
\text { mental health needs of all women who are } \\
\text { victims of abuse, these results show an } \\
\text { additional need of Latin women, those with } \\
\text { low income and high exposure to violence. }\end{array}$ \\
\hline
\end{tabular}


Table 1. Continued.

\begin{tabular}{|c|c|c|c|}
\hline Author (reference) & Objective & Method & Main outcomes \\
\hline Mereish et al. (16) & $\begin{array}{l}\text { To examine ethnicity as the moderator of the } \\
\text { mediator effects of self-esteem about the } \\
\text { relationship between prejudice and depressive } \\
\text { symptoms }\end{array}$ & Cross-sectional & $\begin{array}{l}\text { Important ethnic differences are highlighted } \\
\text { among black men }\end{array}$ \\
\hline Duffy et al. (17) & $\begin{array}{l}\text { Describe the development, feasibility, and } \\
\text { acceptability of a novel preventive intervention } \\
\text { for depression in African American girls living in } \\
\text { urban poverty }\end{array}$ & Clinical trial & $\begin{array}{l}\text { Results indicate that the viability of a novel } \\
\text { preventive intervention for depression in } \\
\text { African Americans was weak, considering that } \\
\text { satisfaction and usability were high. Future } \\
\text { directions to test the efficacy are discussed }\end{array}$ \\
\hline Mrug et al. (18) & $\begin{array}{c}\text { To explain the differences in depressive } \\
\text { symptoms among African American and } \\
\text { European adolescents }\end{array}$ & Cross-sectional & $\begin{array}{l}\text { The family's socioeconomic factors reduced } \\
\text { this difference in } 29 \% \text {; all the risk factors were } \\
\text { reduced in } 88 \% \text {. Exposure of adolescents to } \\
\text { violence, antisocial behavior, and low } \\
\text { connection to school, as well as lower } \\
\text { education of parents and parenthood quality, } \\
\text { appeared as significant mediators of the } \\
\text { differences between groups in depressive } \\
\text { symptoms }\end{array}$ \\
\hline Smith et al. (19) & $\begin{array}{l}\text { To examine to what extent the positive mental } \\
\text { well-being of adolescents and depressive } \\
\text { symptoms vary between the ethnic groups and } \\
\text { to examine prospectively if social support is a } \\
\text { protection against low/poor well-being and } \\
\text { depression. }\end{array}$ & Longitudinal & $\begin{array}{l}\text { Bangladeshi and Black African adolescents in } \\
\text { East London may have a positive advantage } \\
\text { in mental health compared to their white } \\
\text { counterparts from the United Kingdom, even } \\
\text { though social support does not completely } \\
\text { explain the results. }\end{array}$ \\
\hline
\end{tabular}

Table 2. Bias between studies according to the GRADE system.

\begin{tabular}{lc}
\hline Certainty assessment & Depression \\
Number of subjects (studies) Follow-up & 18 observational studies \\
Bias risk & Not severe \\
Inconsistency & Not severe \\
Indirect evidence & Not severe \\
Inaccuracy & Not severe \\
Publication bias & Very strong association \\
Overall certainty of evidence & $\oplus \oplus \oplus \oplus$ High \\
Summary of Results & \\
With black adolescents and children & Present feature/absent feature \\
Relative effect (95\%Cl) & Non-calculable \\
Potential absolute effects & \\
Risk with black adolescents and children & Low $60 / 1000$ \\
Risk difference with risk factors & Not related \\
\hline
\end{tabular}

$\mathrm{Cl}$ : confidence interval.

outcomes point to some of the main risk factors that may be related to mental changes in the population studied.

The GRADE system indicated that there was a high certainty of evidence in the studies due to the small bias level. Table 2 provides the joined bias risk according to GRADE (6) (http://www.jclinepi.com/content/jce-GRADESeries) assessment tool.

Figure 2 shows the calculation of the meta-analysis, a combination of studies on the theme, in which it was possible to determine an effect size of 0.61 with $95 \% \mathrm{Cl}$ (0.55-0.68), which attests that even considering different contexts, the rate of depression in black populations was quite prevalent.

Figure 2 presents the results of the meta-analysis on ethnicity and Figure 3, the publication bias analysis of the studies. Both analyses showed that black children and adolescents in vulnerable social conditions tend to present a strong association $(0.73 ; \mathrm{P}<0.001)$ 


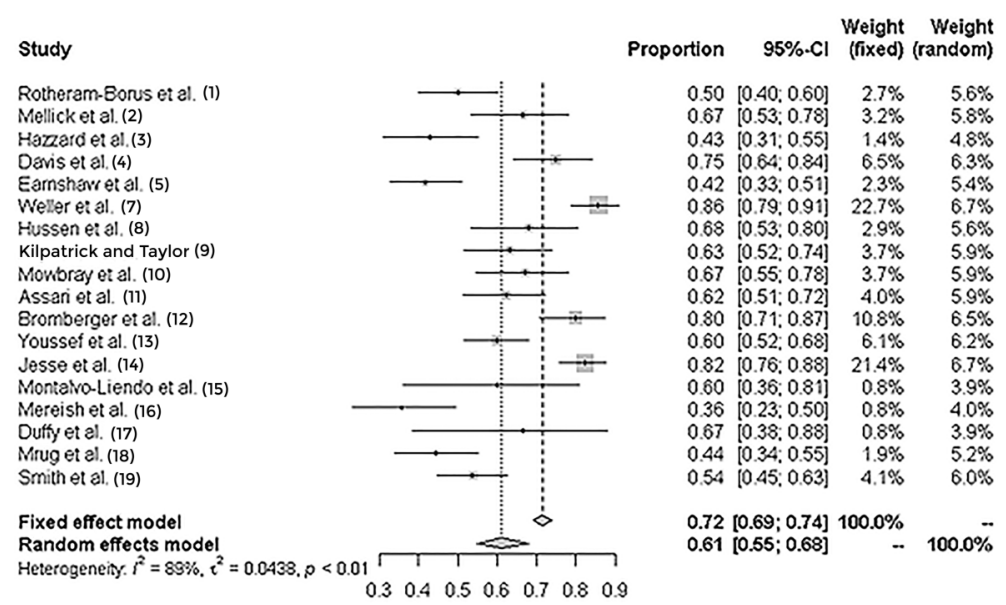

Figure 2. Forest plot of the meta-analysis of ethnicity as a determinant of depression in black children and adolescents.

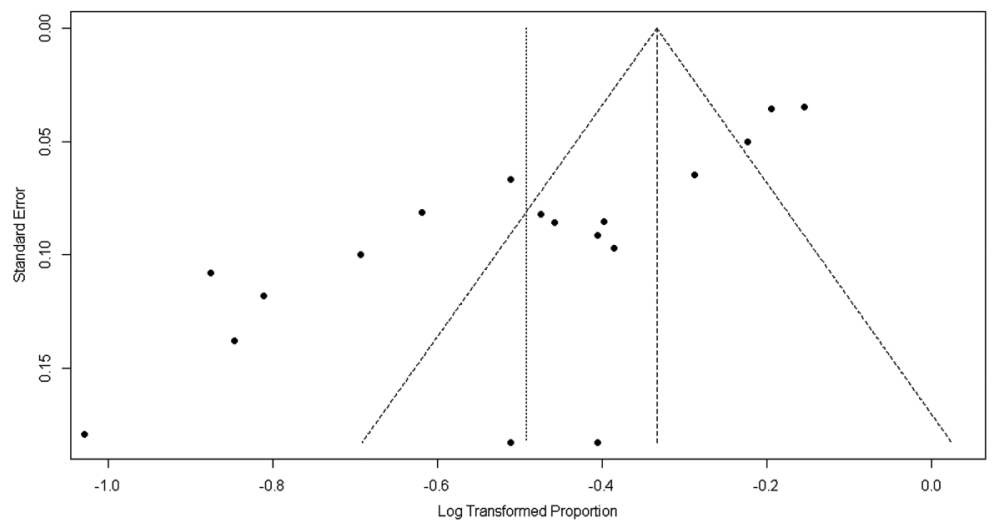

Figure 3. Funnel plot (publication bias).

with depression and mental suffering. Table 2 also presents a summary of the outcomes of the analyzed studies.

\section{Discussion}

The results showed a significant association between ethnicity and depression with a P-value $<0.001$. A study carried out by Weller et al. (7) reported that depression and anxiety were present in $47 \%$ of the individuals. This fact influenced the behavior adopted regarding health, such as lower use of disease preventive methods, and resulted in a larger number of potential diseases.

For Hussen et al. (8), social capital and social relationships determine the vulnerability to certain conditions, like low acquisition of health inputs, which leads to a higher prevalence of some diseases in the black population, such as the human immunodeficiency virus (HIV) infection. This would be an important predictive factor for the 'depression' outcome especially regarding adolescents.

Prejudice issues, which are very common in this context, are also associated with health status. Racism was reported by Kilpatrick and Taylor (9) as an important risk factor for poor health. However, for Mowbray et al. (10), race is independently associated with other sociodemographic variables, because black people with a stable economic condition tend to have an increased risk of developing depression.

In addition, Assari et al. (11) reported that family plays an important role, especially for children and adolescents. Family support in the situations experienced during this period is essential to determine the risk of mental diseases like anxiety and depression. The average age of 15 years has been more associated with a group of economic stressors and limited social resources that result in consequences, including mental alterations (12). 
Ethnic and racial adversity in childhood, including abuse and varied traumas, increase the possibility of depressive symptoms. These events generate resilience levels that affect mental health, especially in the black population $(13,14)$. Gender issues should also be assessed as risk factors for psychic suffering: women are more prone to the development of depression that is also associated with low income and exposure to violence (15-17).

Exposure of adolescents to violence, antisocial behavior, low school attendance, low educational level of parents, and quality of parenthood appeared as significant mediators of differences in depressive symptoms (18). Lower levels of social support are associated with decreased well-being and higher rates of depression in children and adolescents (19).

Based on the discussion and results, we found that race and associated life factors influenced the development of depression in children and adolescents. Some populations, such as individuals from low-income countries, would be more prone to mental health disorders, not

\section{References}

1. Rotheram-Borus MJ, Weichle TW, Wynn A, Almirol E, Davis E, Stewart J, et al. Alcohol, But not depression or IPV, reduces HIV adherence among South African Mothers living with HIV over 5 years. AIDS Behav 2019; 23: 3247-3256, doi: 10.1007/s10461-019-02617-2.

2. Mellick W, Hatkevich C, Venta A, Hill RM, Kazimi I, Elhai JD, et al. Measurement invariance of depression symptom ratings across African American, Hispanic/Latino, and Caucasian adolescent psychiatric inpatients. Psychol Assess 2019; 31: 833-838, doi: 10.1037/pas0000708.

3. Hazzard VM, Hahn SL, Bauer KW, Sonneville KR. Binge eating-related concerns and depressive symptoms in young adulthood: Seven-year longitudinal associations and differences by race/ethnicity. Eat Behav 2019; 32: 90-94, doi: 10.1016/j.eatbeh.2019.01.004.

4. Davis JP, Dumas TM, Merrin GJ, Espelage DL, Tan K, Madden $D$, et al. Examining the pathways between bully victimization, depression, academic achievement, and problematic drinking in adolescence. Psychol Addict Behav 2018; 32: 605-616, doi: 10.1037/adb0000394.

5. Earnshaw VA, Kidman RC, Violari A. Stigma, depression, and substance use problems among perinatally HIV-infected youth in South Africa. AIDS Behav 2018; 22: 3892-3896, doi: 10.1007/s10461-018-2201-7.

6. Moher D, Liberati A, Tetzlaff J, Altman DG, PRISMA Group. Preferred reporting items for systematic reviews and metaanalyses: the PRISMA statement. PLoS Med 2009; 6: e1000097, doi: 10.1371/journal.pmed.1000097.

7. Weller BE, Blanford KL, Butler AM. Estimated prevalence of psychiatric comorbidities in U.S. adolescents with depression by race/ethnicity, 2011-2012. J Adolesc Heal 2018; 62: 716-721, doi: 10.1016/j.jadohealth.2017.12.020.

8. Hussen SA, Easley KA, Smith JC, Shenvi N, Harper GW, Camacho-Gonzalez AF, et al. Social capital, depressive symptoms, and HIV viral suppression among young black, only because of prejudice, but also because of poor socioeconomic factors that contributed to the process.

The main study limitation was the low number of publications regarding mental health in black individuals, especially children and adolescents.

\section{Conclusions}

Race and life conditions are determinants of depression in children and adolescents, with a negative impact in the black population. Social narratives could be investigated for a qualitative determination of feelings and revelations regarding the findings - this study found a statistical association - and how these people feel regarding life aspects should also be taken into consideration.

Black individuals from Portuguese-speaking countries with low socioeconomic levels live in a vulnerable environment that contributes to psychic suffering, and this should be studied in more detail to formulate strategies to reduce the impact on these people.

gay, bisexual and other men who have sex with men living with HIV. AIDS Behav 2018; 22: 3024-3032, doi: 10.1007/ s10461-018-2105-6.

9. Kilpatrick QK, Taylor J. Racial/ethnic contrasts in the relationships between physical disability, perceived discrimination, and depressive symptoms. J Racial Ethn Heal Disparities 2018; 5: 1238-1246, doi: 10.1007/s40615-0180470-5.

10. Mowbray O, Campbell RD, Kim I, Scott JA. Quitting mental health services among racial and ethnic groups of Americans with depression. J Behav Heal Serv. Res 2018; 45: 269-279.

11. Assari $\mathrm{S}$, Caldwell $\mathrm{CH}$. High risk of depression in highincome african american boys. J Racial Ethn Heal Disparities 2018; 5: 808-819, doi: 10.1007/s40615-017-0426-1.

12. Bromberger JT, Schott LL, Matthews KA, Kravitz HM, Harlow SD, Montez JK. Childhood socioeconomic circumstances and depressive symptom burden across 15 years of follow-up during midlife: Study of Women's Health Across the Nation (SWAN). Arch Womens Ment Health 2017; 20: 495-504, doi: 10.1007/s00737-017-0747-4.

13. Youssef NA, Belew D, Hao G, Wang X, Treiber FA, Stefanek $M$, Yassa $M$, et al. Racial/ethnic differences in the association of childhood adversities with depression and the role of resilience. J Affect Disord 2017; 208: 577-581, doi: 10.1016/ j.jad.2016.10.024.

14. Jesse DE, Bian H, Banks EC, Gaynes BN, Hollon SD, Newton ER. Role of Mediators in reducing antepartum depressive symptoms in rural low-income women receiving a culturally tailored cognitive behavioral intervention. Issues Ment Heal Nurs 2016; 37: 811-819, doi: 10.1080/01612 840.2016.1229821.

15. Montalvo-Liendo N, Grogan-Kaylor A, Graham-Bermann S. Ethnoracial variation in depression symptoms. Hisp Heal Care Int 2016; 14: 81-88, doi: 10.1177/1540415316647033. 
16. Mereish EH, N'cho HS, Green CE, Jernigan MM, Helms JE. Discrimination and depressive symptoms among black american men: moderated-mediation effects of ethnicity and self-esteem. Behav Med 2016; 42: 190-196, doi: 10.1080/08964289.2016.1150804.

17. Duffy S, Brown TM, Katsonga-Phiri T, Bouris A, Grant KE, Keenan K. Development of an empirically based preventive intervention for depression in preadolescent african american girls. Prev Sci 2016; 17: 503-512, doi: 10.1007/s11121016-0634-7.
18. Mrug S, King V, Windle M. Brief report: explaining differences in depressive symptoms between African American and European American adolescents. J Adolesc 2016; 46: 25-29, doi: 10.1016/j.adolescence.2015.10.017.

19. Smith NR, Clark C, Smuk M, Cummins S, Stansfeld SA. The influence of social support on ethnic differences in wellbeing and depression in adolescents: findings from the prospective Olympic Regeneration in East London (ORiEL) study. Soc Psychiatry Psychiatr Epidemiol 2015: 50: 17011711, doi: 10.1007/s00127-015-1098-y. 